\title{
Genetic diversity and biogeography of Cunninghamia konishii (Cupressaceae), an island species in Taiwan: a comparison with Cunninghamia lanceolata, a mainland species in China
}

\author{
J.D. Chung ${ }^{\mathrm{a}}$, T.P. Lin ${ }^{\mathrm{b}}$, Y.C. Tan ${ }^{\mathrm{c}}$, M.Y. Lin ${ }^{\mathrm{d}}$, S.Y. Hwang ${ }^{\mathrm{c}, *}$ \\ ${ }^{a}$ Taiwan Forestry Research Institute, 53 Nanhai Rd., Taiwan, ROC \\ ${ }^{\mathrm{b}}$ Institute of Plant Biology, National Taiwan University, Roosevelt Road, Section 4, Taipei, Taiwan, ROC \\ ${ }^{\mathrm{c}}$ Graduate Institute of Biotechnology, Chinese Culture University, 55, Hwagan Rd., Yangmingshan, Taipei, Taiwan, ROC \\ ${ }^{\mathrm{d}}$ Department of Forestry and Natural Resources Conservation, Chinese Culture University, 55, Hwagan Rd., Yangmingshan, Taipei, Taiwan, ROC
}

Received 17 March 2004; revised 10 August 2004

Available online 1 October 2004

\begin{abstract}
Luanta-fir (Cunninghamia konishii), an endemic to Taiwan, is an outcrossing, long-lived conifer. Populations of C. konishii are generally fragmented due to a once high intensity of timber exploitation. C. konishii and Cunninghamia lanceolata are two sibling taxa constituting derivative-progenitor species relationship. The amount of genetic variations within and between 11 and 10 populations of $C$. konishii and $C$. lanceolata, respectively, were assessed using amplified fragment length polymorphism (AFLP) markers in this report. Three AFLP primer pairs generated a total of 357 and 226 markers for C. konishii and C. lanceolata samples, of which 56.1 and $65.3 \%$ are polymorphic, respectively. Analysis of molecular variance indicates a $4.78 \%$ variation between $C$. konishii and $C$. lanceolata. A relatively high value of genetic variation $(24.60 \%)$ was apportioned between the populations of $C$. konishii. In contrast, a lower divergence value $(12.21 \%$ ) between populations was found for $C$. lanceolata. The population with the highest genetic diversity was found in Nantou County, which concurred with the results of many other tree species investigated in Taiwan. The estimates of the number of migrants between populations $(\mathrm{Nm})$, obtained from population pair-wise $\Phi_{\mathrm{ST}}$, suggest that gene flow in $C$. konishii is efficient in some adjacent populations but is restricted in the rest. Individual UPGMA tree, generated based on AFLP markers, suggests six evolutionary lineages for $C$. konishii. All evolutionary lineages of $C$. konishii were derived from $C$. lanceolata. In conclusion, the migration patterns of Cunninghamia from mainland China may have been established following multiple sources, migrant-pools, long-distance dispersal events, and via different directions.
\end{abstract}

(C) 2004 Elsevier Inc. All rights reserved.

Keywords: AFLP; Biogeography; Cunninghamia konishii; Genetic diversity; Taiwan

\section{Introduction}

Population history plays a major role in shaping the spatial distribution of genetic diversity (Schaal et al., 1998; Taberlet et al., 1998). Higher level of allelic richness has been found in source populations than plants in colonized areas (Comps et al., 2001; Widmer and Lexer, 2001). Moreover, the cause for less genetic variability

\footnotetext{
${ }^{*}$ Corresponding author. Fax: +886 228618266.

E-mail address: hsy9347@ms34.hinet.net (S.Y. Hwang).
}

in the islands than in continental populations was attributed to bottleneck or founder effect occurred in island colonization (Barrettt and Shore, 1989; Nei, 1987). Loss of genetic variability is probably a general pattern of species with island-mainland distributions (Frankham, 1997).

The preservation of genetic diversity is a common emphasis of conservation programs. DNA type markers are able to detect the genetic variation beyond coding loci and to provide broader information on the amount of genetic variation and the genetic divergence among 
populations. Amplified fragment length polymorphism (AFLP) has been used successfully in the study of genetic diversity in many plant species (e.g., Keiper and McConchie, 2000; Larson et al., 2001; Muluvi et al., 1999; Palacios et al., 1999). The advantages of this technique include large number of loci assayed, high levels of polymorphisms, high reproducibility, no requirement of prior sequence knowledge, and genome-wide distribution of markers (Powell et al., 1996). Krauss (2000) showed that AFLP, as a dominant marker, is useful for the accurate estimation of genetic diversity. Moreover, AFLP is useful in the estimation of genetic diversity when compared to other types of neutral DNA markers (Powell et al., 1996).

The genus Cunninghamia R. Br. exRich. (Cupressaceae) consists of two extant members distributed in Taiwan and China. Cunninghamia konishii Hay. (=Cunninghamia lanceolata (Lamb.) Hook. var. konishii (Hay.) Fujita) is an endemic species in Taiwan and $C$. lanceolata (Lamb.) Hook. is a species that thrives only in mainland China. In the Tali glacial stage $(50,000-$ 10,000 years ago) during late Pleistocene, C. konishii dominated among other conifers when Taiwan was a part of mainland Asia (Tsukada, 1967). Presently, $C$. konishii is usually found scattered within forests of Chamaecyparis, Pinus spp., and Pseudotsuga wilsoniana at elevations of 1300-2800 m (Liu, 1966). Old growth of C. konishii is a valuable timber source, however, C. konishii is strongly threatened by anthropogenic disturbance of its habitats e.g., about 60 hectares of pure stand of $C$. konishii in Shianshanshan, Hsinchu County, Taiwan was completely deforested. Conservation of this species ex situ in seed orchards requires understanding of its genetic variation within and among natural populations as a first step in defining ex situ conservation programs.

Cunninghamia konishii has the highest genetic diversity $(H e=0.219)$ found among the plant species revealed by allozyme assay from natural populations in Taiwan (Lin et al., 1998) which is higher than the average value reported for many other conifers (average $\mathrm{He}=0.151$, Hamrick et al., 1992). Moreover, the genetic diversity of $C$. lanceolata has also been assayed by allozyme and is significantly higher as compared to $C$. konishii in several studies $(H e=0.299$, Müller-Starck and Liu, 1989; $H e=0.394$, Yeh et al., 1994; $H e=0.343$, Lin et al., 1998). The high level of genetic diversity in C. lanceolata is probably related to the pooling of the $C$. lanceolata genetic materials from initially structured populations during the 2000 years of cultivation (Chen and Shi, 1987; Yeh et al., 1994).

Little genetic differentiation between $C$. lanceolata and $C$. konishii was found and progenitor-derivative species relationship with the latter species differentiated from the former was inferred (Hwang et al., 2003; Lin et al., 1998; Lu et al., 2001). The levels of genetic differentiation analyzed by allozyme variation among populations were 6 and 3\% examined for C. lanceolata and C. konishii, respectively (Lin et al., 1998; Yeh et al., 1994). Low levels of population differentiation in both $C$. lanceolata and $C$. konishii were also found by chloroplast DNA (cpDNA) non-coding sequence data (Hwang et al., 2003). The levels of genetic differentiation among populations of these two Cunninghamia species are similar to those of other gymnosperms and concurred with species that are primarily outcrossing and long-lived (Hamrick et al., 1992). Low level of allozyme and cpDNA differentiation may be taken as evidence that C. konishii populations are genetically homogeneous across its geographic range and thus any population represents the diversity found in the species as a whole. Higher genetic differentiation among populations of forest trees based on neutral DNA markers has been found in Pseudotsuga menziesii (Aagaard et al., 1995), Populus grandidentata (Liu and Furnier, 1993), Pinus leucodermis (Bucci et al., 1997), Chamaecyparis formosensis, and Chamaecyparis taiwanensis (Hwang et al., 2001) in comparison with the allozyme data. Reassessment of population differentiation using neutral DNA type markers such as AFLP is crucial in conservation biology, which can provide information such as gene flow, and population history including the determination of evolutionary lineages (Ennos, 1996).

Genealogical analysis on Cunninghamia was first carried out by examining DNA sequences of one chloroplast intergenic spacer with limited sample size (Lu et al., 2001). Hwang et al. (2003) subsequently examined four chloroplast non-coding DNA sequences with a relatively larger sample size for both Cunninghamia species. Both studies revealed a close relationship between these two species. Furthermore, Lu et al. (2001) proposed a hypothesis of multiple sources and migrant-pool model for Cunninghamia invasion. This hypothesis was supported in part by Hwang et al. (2003) that most individuals from these two species shared the most common ancestral cpDNA haplotype. Sharing of the most common ancestral cpDNA haplotype indicated a possible migrant-pool introduction of Cunninghamia. However, many rare haplotypes (singletons) were derived independently following a glacial population bottleneck. It is therefore interesting to investigate further on the genetic relationship of these two species and to test whether multiple sources with different dispersal directions are likely to be the case in Cunninghamia introduction when more sampling across species ranges and multilocus molecular markers, i.e., AFLP are investigated.

The significance of this work is twofold. First, we investigated the molecular genetic structure in two extant members of Cunninghamia. Second, we assessed the level of gene flow, means of colonization, and the genetic relationship of these two species by individual AFLP haplotype analysis. We found that AFLP polymorphism provided insights that were not detected in 
allozyme and cpDNA studies. We postulate that Cunninghamia invaded Taiwan from multiple sources of mainland China, and following migrant-pools and long-distance dispersal events.

\section{Materials and methods}

\subsection{Plant materials}

Eleven populations encompassing the whole distributional range and accounting for 146 individuals of $C$. konishii were collected from the seed orchard at Chuyunshan, a clonal garden at Lienhuachih Station, Taiwan Forestry Research Institute (TFRI), and from old growths of Shiyuan, Wuser, and Alishan. The sites of the 11 populations sampled in this study are shown in Fig. 1. The Chuyunshan seed orchard was established between 1968 and 1974 at an elevation of $700 \mathrm{~m}$, and was composed of 25 grafted clones planted over 10 hectares. These 25 clones were originated from an old growth of C. konishii and grew at elevations of 1150 $2350 \mathrm{~m}$ in central Taiwan. The Lienhuachih clonal garden, that consists of 139 clones originating from major old-growth forests of $C$. konishii and grew at elevations of 1500-2350 m, was established in June, 1978. Fiftyfour individuals of $C$. lanceolata originating from 44 seed sources from China (10 provenances; expressed as populations) were also collected from the Lienhuachih
Station (Table 1 and Fig. 1). Samples of C. lanceolata were used for the purpose of comparison with C. konishii in the estimation of genetic diversity and population differentiation, and for the examination of the individual genetic relationships.

\subsection{DNA extraction and quantification}

Total DNA was extracted from ground leaf powder according to a modified cetyltrimethyl ammonium bromide (CTAB) procedure (Doyle and Doyle, 1987), which was described in detail by Hwang et al. (2001). DNA was precipitated with ethanol and after washing with $70 \%$ ethanol, it was dissolved in $200 \mu \mathrm{TE}$ buffer, $\mathrm{pH} 8.0$, and placed at $-20^{\circ} \mathrm{C}$. The DNA concentration was determined for each sample using GeneQuant II RNA/DNA Calculator (Amersham-Pharmacia Biotech).

\subsection{AFLP amplification}

AFLP analysis was performed essentially as described in Vos et al. (1995). Genomic DNA (300 ng) was first cut with $5 \mathrm{U}$ of $E c o$ RI restriction enzyme and then ligated with EcoRI adaptor. The EcoRI fragments were then subjected to PCR preamplification with the annealing of E00 pre-selective primers (Table 2). The preamplification was conducted in a reaction solution consisting of $0.15 \mu \mathrm{M}$ E00 and M00 primers, $0.4 \mathrm{U}$

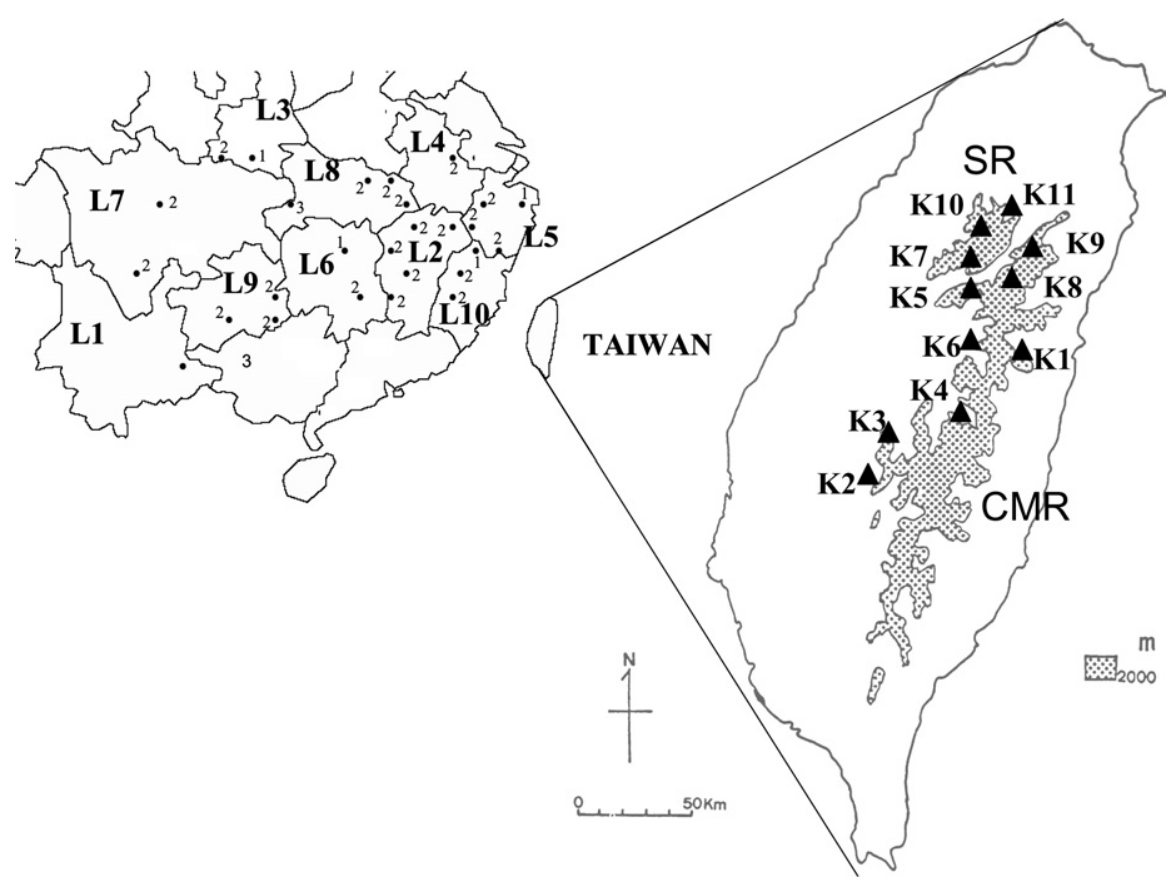

Fig. 1. Sample localities of Cunninghamia konishii and Cunninghamia lanceolata. The hatched area in Taiwan indicates the Shueshan Range (SR) and Central Mountain Ridge (CMR) in Taiwan. Populations K7, K10, and K11 of C. konishii are located in the SR. All other populations are located in the CMR. Population code labeled corresponded to that appeared in Table 1 . The dots and the nearby numbers labeled for $C$. lanceolata in mainland China indicate the original site and number of plants collected. 
Table 1

Site descriptions, specimens, expected heterozygosity $(\mathrm{He})$, total number of amplified bands, percentage of polymorphism $(\% \mathrm{P}, 95 \%$ criterion), and number of private fragments confined to only one population (U) of Cunninghamia lanceolata and C. konishii

\begin{tabular}{|c|c|c|c|c|c|c|c|}
\hline Species and populations (code) & Sample size & Latitude $\left({ }^{\circ} \mathrm{N}\right)$ & Longitude $\left({ }^{\circ} \mathrm{E}\right)$ & $\mathrm{He}$ & Total bands & $\% P$ & $U$ \\
\hline C. konishii & 146 & & & & & & \\
\hline Yeinhai (K1) & 6 & 24.23 & 121.24 & 0.2352 & 78 & 55.1 & 0 \\
\hline Alishan (K2) & 13 & 23.31 & 120.46 & 0.1157 & 152 & 42.8 & 4 \\
\hline Chitou (K3) & 6 & 23.42 & 120.47 & 0.3798 & 73 & 78.7 & 0 \\
\hline Denta (K4) & 17 & 23.80 & 120.70 & 0.1628 & 142 & 59.2 & 0 \\
\hline Tajiann (K5) & 16 & 24.10 & 121.00 & 0.1534 & 199 & 61.3 & 15 \\
\hline Wuser (K6) & 12 & 24.00 & 121.00 & 0.1236 & 88 & 33.3 & 0 \\
\hline Tashueshan (K7) & 8 & 24.30 & 121.10 & 0.2150 & 94 & 67.0 & 0 \\
\hline Shengkuang (K8) & 9 & 24.20 & 121.20 & 0.2212 & 89 & 51.7 & 0 \\
\hline Shiyuan (K9) & 11 & 24.26 & 121.20 & 0.1191 & 71 & 31.7 & 0 \\
\hline Kuanwu (K10) & 29 & 24.75 & 121.10 & 0.1140 & 214 & 67.3 & 14 \\
\hline Shiouhluan (K11) & 19 & 24.50 & 121.10 & 0.1815 & 186 & 68.8 & 6 \\
\hline Average & & & 0.1838 & 113.3 & 56.1 & & \\
\hline C. lanceolata & 54 & & & & & & \\
\hline Yunnan (L1) & 3 & 23.00 & 104.21 & 0.3408 & 59 & 91.5 & 0 \\
\hline Jiangxi (L2) & 10 & $26.50-28.30$ & $114.10-114.25$ & 0.2088 & 73 & 52.0 & 0 \\
\hline Sanxi (L3) & 3 & $33.05-33.15$ & 107.00 & 0.3619 & 86 & 95.3 & 0 \\
\hline Anhuei (L4) & 2 & 32.50 & 118.20 & 0.3604 & 39 & 59.0 & 0 \\
\hline Zheijiang (L5) & 9 & $28.06-29.50$ & $118.35-120.90$ & 0.2189 & 118 & 54.2 & 0 \\
\hline Hunan (L6) & 3 & $26.52-25.80$ & $109.41-113.00$ & 0.3749 & 36 & 72.2 & 0 \\
\hline Xichuan (L7) & 4 & $28.30-30.06$ & $104.00-104.40$ & 0.2962 & 61 & 96.7 & 0 \\
\hline Hubei (L8) & 9 & $29.90-31.70$ & $106.00-114.20$ & 0.1786 & 112 & 41.1 & 1 \\
\hline Gueizhou (L9) & 6 & $26.00-26.55$ & $107.80-109.50$ & 0.2731 & 47 & 40.4 & 0 \\
\hline Fuzeing (L10) & 5 & $26.80-27.90$ & $117.80-118.75$ & 0.2490 & 73 & 50.7 & \\
\hline Average & & & & 0.2863 & 70.4 & 65.3 & \\
\hline
\end{tabular}

Table 2

Adaptors and primers used for AFLP selective amplification

\begin{tabular}{lll}
\hline Adaptor site & Adaptor code & Adaptor sequence \\
\hline EcoRI & Ecol & 5'-CTCGTAGACTGCGTACC-3' \\
& & 3'-CTGACGCATGGTTAA-5' $^{\prime}$ \\
MseI & Mse1 & $5^{\prime}$-GACGATGAGTCCTGAG-3' \\
& & $3^{\prime}$-TACTCAGGACTCAT-5' \\
Pre-selective & E00 & 5'-GACTGCGTACCAATTC-3' \\
primers & M00 & $5^{\prime}$-GATGAGTCCTGAGTAA-3' \\
Selective & E00 + G & $5^{\prime}$-GACTGCGTACCAATTCG-3' \\
primers & M00 + AG & $5^{\prime}$-GATGAGTCCTGAGTAAAG-3' \\
& M00 + CT & $5^{\prime}$-GATGAGTCCTGAGTAACT-3' \\
& M00 + GT & $5^{\prime}$-GATGAGTCCTGAGTAAGT-3' \\
\hline
\end{tabular}

Taq polymerase, $0.5 \mu \mathrm{g} / \mu \mathrm{l}$ R Nase, and $0.1 \mu \mathrm{M}$ dNTPs in a reaction buffer $(50 \mathrm{mM} \mathrm{KCl}, 1.5 \mathrm{mM} \mathrm{MgCl} 2,10 \mathrm{mM}$ Tris- $\mathrm{HCl}, \mathrm{pH} 9.0$ ), to obtain a final reaction volume of $10 \mu \mathrm{l}$. The PCR program for preamplification was 20 cycles of $30 \mathrm{~s}$ at $94{ }^{\circ} \mathrm{C}, 1 \mathrm{~min}$ at $56^{\circ} \mathrm{C}$, and $1 \mathrm{~min}$ at $72^{\circ} \mathrm{C}$. The PCR preamplification was carried out using a Robocycler GRADIENT 96 temperature cycler (Stratagene). One microliter of this PCR product was then subjected to a second round of PCR amplification with Cy5 (Indodicarbocyanine phosphoramidite) labeled $\mathrm{E} 00+\mathrm{G}$ and $\mathrm{M} 00+2$ primers (Table 2). The second round of PCR was conducted in a DNA Programmable Thermal Cycler (MJ Research). The fragments were amplified first at $94{ }^{\circ} \mathrm{C}$ for 3 min for 12 PCR cycles
(30 s at $94{ }^{\circ} \mathrm{C}, 30 \mathrm{~s}$ at $65^{\circ} \mathrm{C}$ with $0.5^{\circ} \mathrm{C}$ touchdown per cycle, and $1 \mathrm{~min}$ at $72^{\circ} \mathrm{C}$ ), and then for 23 PCR cycles at $94{ }^{\circ} \mathrm{C}$ for $30 \mathrm{~s}, 30 \mathrm{~s}$ at $56^{\circ} \mathrm{C}$, and $1 \mathrm{~min}$ at $72{ }^{\circ} \mathrm{C}$, and the last step was $5 \mathrm{~min}$ at $72^{\circ} \mathrm{C}$. The PCR products were separated by using $8 \%$ ReproGel High Resolution kit (Amersham-Pharmacia Biotech). The molecular size marker used was the Cy5 labeled $50-500 \mathrm{bp}$ ladder. Electrophoresis was conducted on ALF Express II DNA Analysis System and the DNA fragments were recorded by ALFwin Fragment Analysis 1.01 software (Amersham-Pharmacia Biotech).

\subsection{Data collection and analysis}

All polymorphic bands were scored for the presence (1)/absence (0) across all loci. The computer program TFPGA (Tools for Population Genetic Analysis) was used to provide information on genetic diversity $(\mathrm{He})$ for each population (Miller, 1997a). Average heterozygosity was calculated for each locus and averaged over loci according to the unbiased formula of Nei (1978). The AMOVAPREP program (Miller, 1997b) was used to prepare dominant marker data for AMOVA analysis. Components of variance partitioned within and between populations were estimated from a Euclidean distance matrix using WINAMOVA version 1.55 (analysis of molecular variance, Excoffier et al., 1992). The significance of AMOVA variance components was tested 
using non-parametric permutation procedures. The AMOVA variance components were used as estimates of the genetic diversity within and between populations. By using Bartlett's test, the data were also tested for the assumption of homogeneity of molecular variance among populations and carried out simultaneously by WINAMOVA program. The UPGMA algorithm of Sneath and Sokal (1973) was used to generate a haplotype dendrogram. This algorithm was performed with SAHN (sequential, agglomerative, hierarchical, and nested clustering) routine using NTSYS-pc software version 2.0 (Exeter Software, Setauket, NY) based on a Jaccard's similarity matrix (Jaccard, 1908). This similarity algorithm was chosen because it ignores $0 / 0$ matches, and is appropriate for molecular marker data producing only dominant bands.

\section{Results}

\subsection{AFLP variation and genetic diversity}

Initially, the AFLP procedure was conducted on a sample of 40 plants from 11 and 10 populations of $C$. konishii and $C$. lanceolata, respectively, to test the availability of 15 AFLP primer pairs. Only three AFLP primer pairs generated reproducible and unequivocally scorable fragments for further analysis. These three AFLP primer pairs employed generated a total of 357 and 226 markers for $C$. konishii and C. lanceolata, respectively. The molecular weights of the polymorphic fragments counted ranged in size from 50 to $350 \mathrm{bp}$. The $H e$, total number of amplified bands, percent polymorphism, and private fragments for populations are shown in Table 1. The percent polymorphism that ranged 33.3$78.7 \%($ mean $=56.1 \%)$ and $40.4-96.7 \%($ mean $=65.3 \%)$ was detected across $C$. konishii and C. lanceolata populations, respectively. One hundred and thirty-five AFLP haplotypes were obtained for 146 C. konishii individuals and 54 were found for 54 C. lanceolata. The four populations in C. konishii that had population-specific AFLP fragments were Kuanwu 14, Alishan 4, Tajiann 15, and
Shiouhluan 6, respectively. Hubei in C. lanceolata had one population-specific AFLP fragment.

The genetic diversity measures were estimated using TFPGA software (Miller, 1997a). Estimates of genetic diversity using AFLP data ranged from 0.1786 to 0.3749 with an average of 0.2863 in C. lanceolata. Hunan population had the highest $\mathrm{He}$ of 0.3749 and Hubei population had the lowest $\mathrm{He}$ of 0.1786 for $\mathrm{C}$. lanceolata. Estimates of genetic diversity ranged from 0.1140 to 0.3798 with a mean of 0.1838 in C. konishii. Kuanwu population had the lowest $\mathrm{He}$ and Chitou had the highest $\mathrm{He}$ despite its small sample size examined. The population with the highest heterozygosity was found at a latitude of $23.42^{\circ}$ corresponding to Chitou, which is located in Nantou County of central Taiwan. The Shengkuang, Shiouhluan, Yeinhai, and Tashueshan populations located between latitudes $24.20^{\circ}$ and $24.50^{\circ}$ also had high level of genetic variability.

\subsection{Species divergence and population structure among populations}

Genetic differentiation between $C$. konishii and $C$. lanceolata was low using AFLP markers $\left(\Phi_{\mathrm{CT}}=0.048\right.$, $P=0.016$ ) by AMOVA analysis (Table 3 ). The extent of genetic differentiation among populations was $24.6 \%\left(\Phi_{\mathrm{ST}}=0.246, P<0.001\right.$ with 1000 non-parametric permutation, Table 3 ) and Bartlett's heterogeneity test was significant in C. konishii $\left(\chi^{2}=37.34\right.$, $\mathrm{df}=10$, $P<0.001)$. The matrix of the pair-wise geographic distance $(\mathrm{km})$ was not correlated with the corresponding matrix of pair-wise $\Phi_{\mathrm{ST}}$ (Fig. 2; Mantel test: $r=0.038$; $P=0.0299$ with 1000 permutation). The effective number of migrants $(\mathrm{Nm})$ for each population pair was calculated for the 11 populations of $C$. konishii, the most likely to exchange individuals (Table 4). Pair-wise $\Phi_{\mathrm{ST}}$ values and the effective number of migrants indicated that the comparison of most population pairs differ significantly. Using AFLP high resolution markers, we found that the average number of migrants was 1.65 for populations of C. konishii and was moderate. Unexpected high levels of gene flow was found between

Table 3

Analysis of molecular variance based on AFLP amplification products

\begin{tabular}{|c|c|c|c|c|c|}
\hline Source of variation & df & SSD & MSD & Variance component & $\%$ of total $(P)$ \\
\hline C. konishii and C. lanceolata & 1 & 148.40 & 148.40 & 1.10 & $4.78(=0.016)$ \\
\hline $\begin{array}{l}\text { C. konishii } \\
\text { Among populations } \\
\text { Within populations } \\
\text { Total }\end{array}$ & $\begin{array}{r}10 \\
135 \\
145\end{array}$ & $\begin{array}{r}895.66 \\
2305.93\end{array}$ & $\begin{array}{l}89.57 \\
17.60\end{array}$ & $\begin{array}{r}5.74 \\
17.60\end{array}$ & $\begin{array}{l}24.60(<0.001) \\
75.40\end{array}$ \\
\hline $\begin{array}{l}\text { C. lanceolata } \\
\text { Among populations } \\
\text { Within populations } \\
\text { Total }\end{array}$ & $\begin{array}{r}9 \\
44 \\
53\end{array}$ & $\begin{array}{l}247.33 \\
699.42 \\
946.75\end{array}$ & $\begin{array}{l}27.48 \\
15.90\end{array}$ & $\begin{array}{r}2.21 \\
15.90\end{array}$ & $\begin{array}{l}12.21(<0.001) \\
87.79\end{array}$ \\
\hline
\end{tabular}

Levels of significance are based on 1000 random permutations. 


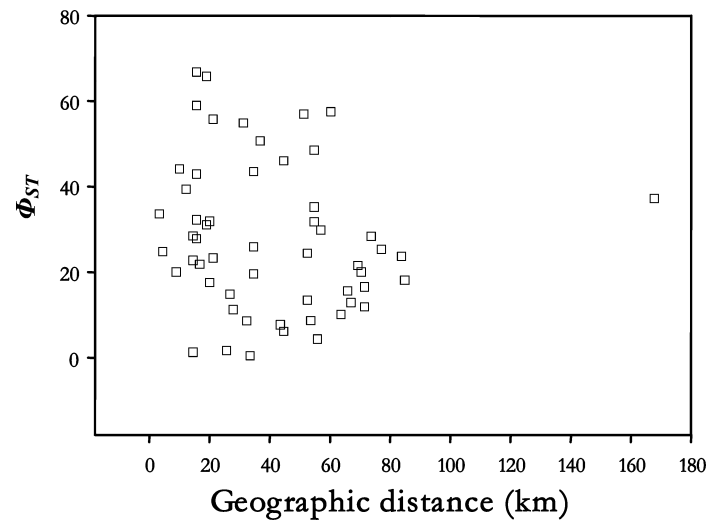

Fig. 2. Plot of the pair-wise $\Phi_{\mathrm{ST}}$ values plotted against geographic distance (Mantel test) in the Cunninghamia konishii populations.

Yeinhai and Alishan $(\mathrm{Nm}=14.71)$, between Alishan and Chitou $(\mathrm{Nm}=50.00)$, and between Denta and Shiouhluan $(N m=18.66)$. Only $12.2 \%\left(\Phi_{\mathrm{ST}}=0.122, P<0.001\right.$ with 1000 non-parametric permutation) of the genetic differentiation was found among populations of $C$. lanceolata, and Bartlett's heterogeneity test was found to be insignificant $\left(\chi^{2}=1.62\right.$, $\mathrm{df}=9, P=0.059$, Table $3)$. Pair-wise $\Phi_{\mathrm{ST}}$ values and the effective number of migrants were not estimated for $C$. lanceolata populations because of the pooling of genetic materials.

Interestingly, through the calculation of the average $\Phi_{\mathrm{ST}}$ for individual C. konishii population in comparison with every other population, we found that Tashueshan (K7) was genetically the most distinct population followed by Shiyuan (K9) and Chitou (K3) (Fig. 3).

\subsection{Genetic relationships of Cunninghamia individuals}

Individual UPGMA tree revealed that $C$. konishii would originate from $C$. lanceolata (Fig. 4). Six clusters of Cunninghamia were classified in this dendrogram. The first major cluster (cluster A) represented individuals from populations $\mathrm{K} 6, \mathrm{~K} 9$, and $\mathrm{K} 10$ of C. konishii. Cluster $\mathrm{B}$ contained only those individuals from $\mathrm{K} 2, \mathrm{~K} 3, \mathrm{~K} 4$,

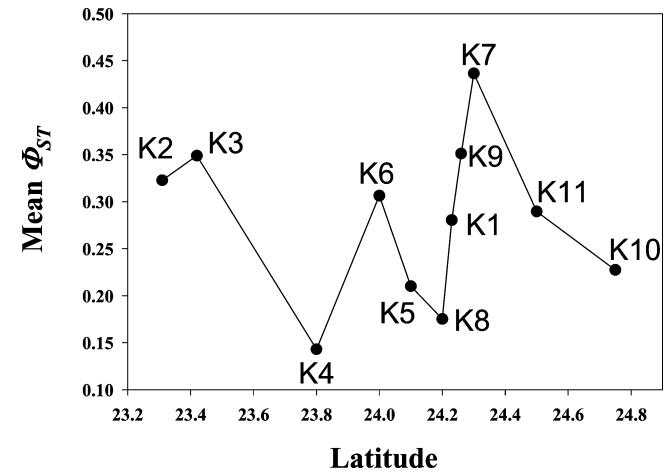

Fig. 3. Plot of the mean $\Phi_{\mathrm{ST}}$ values of each population compared to every other population against the population latitude in Cunninghamia konishii. Population code labeled corresponded to that appeared in Table 1.

$\mathrm{K} 8$, and $\mathrm{K} 9$ of $C$. konishii. Cluster $\mathrm{C}$ was composed of individuals from $\mathrm{K} 2, \mathrm{~K} 5$, and $\mathrm{K} 10$ of $C$. konishii and individuals of $C$. lanceolata. In cluster $\mathrm{D}$, individuals from $\mathrm{K} 1, \mathrm{~K} 4, \mathrm{~K} 5, \mathrm{~K} 7, \mathrm{~K} 8$, and $\mathrm{K} 11$ of $C$. konishii were derived from individuals of Sanxi, Hubei, Gueizhou, and Fuzeing of $C$. lanceolata. Cluster E consisted of individuals from $\mathrm{K} 2, \mathrm{~K} 4$, and $\mathrm{K} 8$ of $C$. konishii and two individuals of $C$. lanceolata. The $\mathrm{F}$ cluster consisted mostly of $C$. lanceolata and two individuals of $C$. konishii. All individuals of K1, K3, K6, K7, and K11 populations of $C$. konishii were grouped together in respective clusters. However, individuals of the C. konishii populations $\mathrm{K} 2, \mathrm{~K} 4, \mathrm{~K} 5, \mathrm{~K} 8, \mathrm{~K} 9$, and $\mathrm{K} 10$ were scattered in different clusters.

\section{Discussion}

\subsection{Genetic diversity based on AFLP markers}

The AFLP analysis was very efficient in detecting genetic variation in the genomes of both $C$. konishii and $C$. lanceolata. No population was characterized monomorphic using the AFLP polymorphisms. Higher number of

Table 4

Pairwise $\Phi_{\mathrm{ST}}$ values (below diagonal) and the effective number of migrants ( $\mathrm{Nm}$ ) (above diagonal) illustrating population divergence in Cunninghamia konishii analyzed by AMOVA

\begin{tabular}{llllllllllll}
\hline & K1 & K2 & K3 & K4 & K5 & K6 & K7 & K8 & K9 & K10 & K11 \\
\hline K1 & & 14.7059 & 1.1416 & 1.9380 & 1.0979 & 0.6342 & 0.4241 & 1.2456 & 0.5429 & 1.0068 & 0.7869 \\
K2 & 0.0170 & $* * *$ & 50.0000 & 1.5423 & 0.8964 & 0.5743 & 0.3801 & 1.0221 & 0.4483 & 0.7835 & 0.4553 \\
K3 & 0.2190 & 0.005 & $* * *$ & 1.5060 & 0.8781 & 0.5663 & 0.3743 & 1.0540 & 0.4390 & 0.7750 & 0.4346 \\
K4 & 0.1290 & 0.1621 & 0.1660 & $* * *$ & 5.6818 & 0.9866 & 0.8381 & 2.2163 & 1.6779 & 2.4704 & 18.6567 \\
K5 & 0.2277 & 0.2789 & 0.2847 & 0.0440 & $* * *$ & 1.0711 & 0.7423 & 1.5985 & 0.9634 & 1.2463 & 3.2216 \\
K6 & 0.3942 & 0.4353 & 0.4415 & 0.2534 & 0.2334 & $* * *$ & 1.4188 & 1.3759 & 0.7096 & 0.8036 & 0.8806 \\
K7 & 0.5895 & 0.6578 & 0.6679 & 0.2983 & 0.3368 & 0.1762 & $* * *$ & 0.4931 & 0.4931 & 0.5823 & 0.5149 \\
K8 & 0.2007 & 0.2446 & 0.2372 & 0.1128 & 0.1564 & 0.1817 & 0.2159 & $* * *$ & 1.2749 & 2.0991 & 2.8902 \\
K9 & 0.4605 & 0.5577 & 0.5695 & 0.149 & 0.2595 & 0.3523 & 0.5070 & 0.1961 & $* * *$ & 2.8670 & 0.6713 \\
K10 & 0.2483 & 0.3191 & 0.3226 & 0.1012 & 0.2006 & 0.3111 & 0.4293 & 0.1191 & 0.0872 & $* * *$ & 1.8519 \\
K11 & 0.3177 & 0.5491 & 0.5752 & 0.0134 & 0.0776 & 0.2839 & 0.4855 & 0.0865 & 0.3724 & 0.1350 & $* * *$ \\
\hline
\end{tabular}




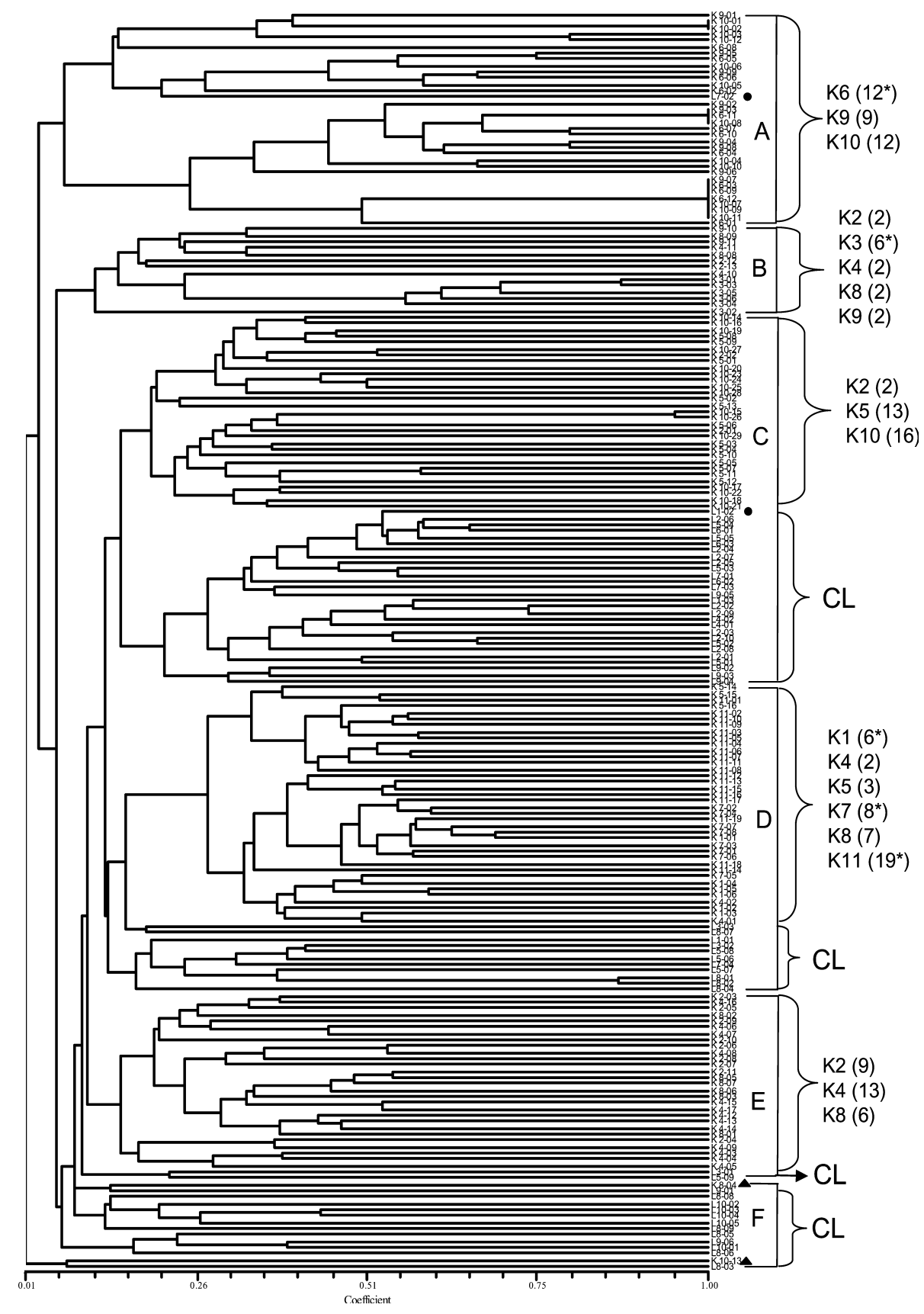

Fig. 4. Individual UPGMA tree. UPGMA algorithm of Sneath and Sokal (1973) was performed with SAHN routine using NTSYS-pc software version 2.0 (Exeter Software, Setauket, NY) based on a Jaccard's similarity matrix. Dots indicate misplacement of Cunninghamia laneolata with $C$. konishii. Triangle indicates $C$. konishii grouped with $C$. lanceolata in the base of the UPGMA tree. Six clusters were represented by A, B, C, D, E, and F. On the right of each cluster where population code labeled for $C$. konishii such as K3 (6*) indicates Chitou population of $C$. konishii, the number in the parenthesis indicates the number of individuals from this population grouped in that cluster; the star symbol represents all individuals from the population are grouped together in the same cluster.

resolved AFLP haplotypes indicated the existence of higher levels of genetic variations in the analyzed populations for both species. In general, AFLP generated a large number of polymorphic DNA fragments. The technical advantage of AFLP is that the accuracy of measurements of genetic distance increases with the number of loci examined (Travis et al., 1996). In this
AFLP investigation, the average genetic diversity of $C$. konishii in Taiwan was considerable, but still greatly less in comparison with its presumed progenitor C. lanceolata both by allozyme (Lin et al., 1998) and AFLP (this study) assays. Population-specific AFLP fragments were more common in the populations of $C$. konishii than those of $C$. lanceolata. This could be resulted from the 
genetic drift and population bottleneck occurred in the island species. Depauperate levels of genetic variation may be expected in a colonizing species if there are a low number of source populations and a high number of bottleneck events (Affre et al., 1997) resulting in reduced genetic variation since the introduction of Cunninghamia from mainland Asia to Taiwan.

Furthermore, the lower average genetic diversity found in C. konishii corresponded to the lower genetic variation observed in the marginal populations in comparison with more central populations located in mainland Asia. In many plants including gymnosperms and angiosperms, decrease in genetic variability towards species margins has been reported such as Quercus spp. (Dumolin-Lapègue et al., 1997), Fagus sylvatica (Demesure et al., 1996), Pinus monticola (Steinhoff et al., 1983), and Picea mariana (Yeh et al., 1986). This central-marginal decline in genetic variability is probably related to the hindrance of gene flow by effective barriers or the fragmentation and/or bottleneck of populations.

The geographical region in central Taiwan has been proposed as the major diversity center for several forest species based on allozyme variation (Lin, 2001). These species include Myrica rubra (Lour.) Sieb and Zucc. (Cheng et al., 2000), Cinnamomum kanehirae Hay. (Lin et al., 1997), C. konishii Hay. (Lin et al., 1998), and Trochodendron aralioides Sieb and Zucc (Wu et al., 2001). Moreover, island wide samplings of $T$. aralioides found a secondary diversity center between latitudes $24.7^{\circ}$ and $25.0^{\circ}$. In C. konishii, the highest level of genetic diversity was found in Chitou population and was consistent with the results of allozyme data that the Nantou County in central Taiwan as the major diversity center harboring the greatest genetic variation for many plant species in Taiwan (Lin, 2001). Interestingly, populations around latitude $24.3^{\circ}$ with relatively higher level of genetic variability assayed using AFLP polymorphism in this study concurred with the findings of allozyme data in several studies including C. konishii (Lin et al., 1998), T. aralioides (Wu et al., 2001), Alnus formosana (Sue et al., 2000), and Taiwania cryptomerioides (Lin et al., 1993). Similar results were also observed for cpDNA data from $T$. aralioides (Huang et al., 2004) and Castanopsis carlesii (Cheng et al., unpublished data).

\subsection{Refugia inference for Cunninghamia konishii}

The degree of average $\Phi_{\mathrm{ST}}$ of each population in comparison with that of the remaining populations can be used to examine the consequences of historical and contemporary geographical population subdivision on evolutionary processes related to genetic variability (Johnson et al., 2000), and is important for reconstructing the phylogeographical history evolved during pre- and post-colonization events (Grant and Grant,
1997). A recent study shows that cpDNA variation in 22 widespread European trees and shrubs had genetically divergent populations in the Mediterranean regions that corresponded to the sites of glacial refugia (Petit et al., 2003). Interestingly, the region around Chitou and Alishan populations located in the Central Mountain Ridge (CMR), and the region around Tashueshan and Shiyuan populations located in Shueshan Range (SR) (Fig. 1), the two genetically divergent regions (Fig. 3), are probably the glacial refugia when the average temperature is $8-11^{\circ} \mathrm{C}$ lower during glacial maximum in contrast to the present-day temperature (Tsukada, 1967). These two sites coincide with the region of major and secondary diversity centers mentioned above.

\subsection{Species divergence and population differentiation}

The $4.8 \%$ genetic divergence between $C$. konishii and C. lanceolata suggests their conspecific relationship. The lack of genetic divergence within the two species of $\mathrm{Cun}$ ninghamia is consistent with the results analyzed by allozyme (Lin et al., 1998) and cpDNA variations (Hwang et al., 2003; Lu et al., 2001).

Higher population divergence $(24 \%)$ found in $C$. konishii using AFLP markers in contrast to allozyme data (3\%, Lin et al., 1998) is consistent with the results of other plant species when using dominant markers such as RAPD in contrast to codominant allozyme data (Aagaard et al., 1995; Bucci et al., 1997; Hwang et al., 2001; Liu and Furnier, 1993). The higher level of genetic differentiation revealed by AFLP was also reported for other plant species (e.g., Cardoso et al., 2000; Gaudeul et al., 2000; Palacios et al., 1999). Recently, higher value of genetic differentiation is observed based on RAPD markers for the threatened South American conifer Pilgerodendron vuiferum (Cupressaceae) (Allnutt et al., 2003).

However, lower level of genetic differentiation among populations found in this study for $C$. lanceolata could be ascribed in part to the pooling of the $C$. lanceolata genetic materials (Yeh et al., 1994). Groupings according to ecotypes (Yu, 1996) failed to correlate well with either isozyme allele frequencies or heterozygosities in mature trees (Yang et al., 2000). Nine enzyme systems were used to investigate 16 populations of $C$. lanceolata in China, no correlation was found between the distribution of genetic diversity and both the geographic and climatic variables of the species, and this might have been caused by the lack of genetic isolation in the species (Yeh et al., 1994). Even though local populations of cultivated selections may contribute to the level of genetic diversity, interbred of different sources of C. lanceolata might have occurred and resulted in the lower level of genetic differentiation in contrast to $C$. konishii. 


\subsection{Gene flow and biogeography}

Indirect estimates of gene flow measure the cumulative effect of migration acting over all temporal and spatial scales (Neigel, 1997). Gene flow in C. konishii would occur mainly due to the movement of pollens and seeds. The comparison of $N m$ values obtained from $\Phi_{\mathrm{ST}}$ estimates suggests that high level of migration may have occurred for Yeinhai-Alishan, Alishan-Chitou, DentaTajiann, and Denta-Shiouhluan population pairs. Although high level of effective number of migrants might only reflect ancestral relationships, coupled factors of easily dispersed light seed and typhoon visiting during summer and autumn with high winds would have facilitated extensive gene flow among some adjacent populations, especially for Alishan and Chitou. The event of gene flow in C. konishii has not been limited to between nearest neighboring populations because individuals from those distant populations such as Shiyuan and Alishan are also grouped in the same cluster (cluster B) (Fig. 4). Effective gene flow, typical of most wind-pollinated conifers, would be hindered by local environmental differences that resulted in the failure of successful dispersal. Although a migration rate of 0.5 was considered sufficient to overcome the diversifying effects of random drift (Ellstrand and Elam, 1993), lower values of effective number of migrants observed in $C$. konishii might have resulted in a genetic drift in some populations.

Historical factors are also essential in the interpretation of the current patterns of genetic differentiation when using molecular markers in the analysis of the patterns of genetic variation (Newton et al., 1999). The present-day structure of genetic variation may be due to past decrease in population size rather than limited gene flow. Moreover, the observed genetic structure of C. konishii in this study might have derived from severe bottlenecks in some populations because low effective size of populations would have increased the genetic drift resulting in the loss of allelic diversity as that might have occurred in populations including Alishan, Denta, Tajiann, Wuser, Shiyuan, Shiouhluan, and Kuanwu. The large number of unique fragments found in Tajiann and Kuanwu further support the occurrence of bottleneck event during the past in this species.

Non-homogeneous genetic differentiation in C. konishii populations is probably associated with historical demographic changes among sampling sites. Despite an observed average moderate level of migration, the effective number of migrants between Tashueshan and Shiyuan, and between Shiyuan and Chitou were low. It is likely that Shiyuan with low genetic diversity and high divergence from the rest of populations suggests its small population size and limited recruitment by seed during postglacial colonization from glacial refugia. The overall pattern of genetic divergence among C. konishii populations reflects a history of separation and/or differences in the effective population size that is related to the bottleneck event (Hwang et al., 2003). An exception is the population from Denta, which displays a relatively higher level of migration event probably related to its geographic location that may play as a waypoint for migration.

Taiwan hosts more than 4000 species of vascular plants distributed from the sea level to $3900 \mathrm{~m}$ in elevation and is rich in endemism (Hsieh, 2002). Most of these plants are distributed within one of four floristic regions delimited distinctly in altitudes (Hsieh et al., 1994). It is unlikely that competitions of Cunninghamia with Pinus spp., Chamaecyparis, and $P$. wilsoniana (Liu, 1966) as well as many other plant species for successful dispersal and survival in the local environments lead to successful introduction from only one single source. It is also quite impossible that from a single source of Cunninghamia introduction, the local spread occurred effectively despite niche competition and preemption (Silvertwon, 2004).

Multiple sources of Cunninghamia introduction are revealed by individual UPGMA tree (Fig. 4). This dendrogram reveals a pattern of individual groupings studded with an intermingling of different populations in $C$. konishii. One possible scenario ascribed to explain the intermingling of haplotypes is the multiple source introductions of Cunninghamia onto Taiwan via different directions in migrant pools and subsequently spread through local movements of these genetic variations after colonization. The multiple sources of Cunninghamia introduction from continental Asia via migrantpool, long-distance seed dispersal had also been proposed (Lu et al., 2001). In this study, four migrant pools can be classified corresponding to the individuals of $C$. lanceolata in clusters C, D, E, and (A, B) (Fig. 4). The two individuals of $C$. lanceolata grouped with many individuals of $C$. konishii from various populations are possibly due to historical migration events instead of long-distance dispersal after glacial maximum. The same scenario could be applied to the two $C$. konishii individuals that were grouped together with individuals of $C$. lanceolata in cluster F.

\section{Acknowledgments}

This investigation was funded by the National Science Council (Grant No. NSC91-2313-B-034-003), Executive Yuan, Taiwan. We express our sincere gratitude to Mr. Ji-Shen Wu, Division of Silviculture, Taiwan Forestry Research Institute, for his kind help in the sample collections. Helpful comments from two anonymous reviewers in a previous version of this paper are also acknowledged. 


\section{References}

Aagaard, J.E., Vollmer, S.S., Sorensen, F.C., Strauss, F.C., 1995. Mitochondrial DNA products among RAPD profiles are frequent and strongly differentiated between races of Douglas-fir. Mol. Ecol. $4,441-446$.

Affre, L., Thompson, J.D., Debussche, M., 1997. Genetic structure of continental and island populations of the Mediterranean endemic Cyclamen balearum (Primulaceae). Am. J. Bot. 84, 437-451.

Allnutt, T.R., Newton, A.C., Premoli, A., Lara, A., 2003. Genetic variation in the threatened South American conifer Pilgerodendron vuiferum (Cupressaceae), detected using RAPD markers. Biol. Conserv. 114, 245-253.

Barrettt, S.C.H., Shore, J.S., 1989. Isozyme variation in colonizing plants. In: Soltis, D.E., Soltis, P.S. (Eds.), Isozymes in Plant Biology. Dioscorides Press, Portland, OR, pp. 106-126.

Bucci, G., Vendramin, G.G., Lelli, L., Vicario, F., 1997. Assessing the genetic divergence of Pinus leucodermis Ant. endangered populations: use of molecular markers for conservation purposes. Theor. Appl. Genet. 95, 1138-1146.

Cardoso, S.R.S., Eloy, N.B., Provan, J., Cardoso, M.A., Ferreira, P.C.G., 2000. Genetic differentiation of Euterpe edulis Mart. populations estimated by AFLP analysis. Mol. Ecol. 9, 1753-1760.

Chen, Y.W., Shi, J.S., 1987. Genetic variation and improvement program of Chinese fir. J. Subt. For. Inst. 1, 1-19.

Cheng, Y.P., Chien, C.T., Lin, T.P., 2000. Population genetics of geographically restricted and widespread species of Myrica (Myricaceae). J. Hered. 91, 61-66.

Comps, B., Gömöry, D., Letouzey, J., Thiébault, B., Petit, R.J., 2001. Diverging trends between heterozygosity and allelic richness during postglacial colonization in the European beech. Genetics 157, 389397.

Demesure, B., Comps, B., Petit, R.J., 1996. Chloroplast DNA phylogeography of the common beech (Fagus sylvatica L.) in Europe. Evolution 50, 2515-2520.

Doyle, J.J., Doyle, J.L., 1987. A rapid DNA isolation procedure for small quantities of fresh leaf material. Phytochem. Bull. 19, 11-15.

Dumolin-Lapègue, S., Demesure, B., Fineschi, S., Le Corre, V., Petit, R.J., 1997. Phylogenetic structure of white oaks throughout the European continent. Genetics 146, 1475-1487.

Ellstrand, N.C., Elam, D.R., 1993. Population genetic consequences of small population size: impications for plant conservation. Annu. Rev. Ecol. Syst. 24, 217-242.

Ennos, R.A., 1996. Utilising genetic information in plant conservation programmes. In: Hochberg, W.E., Clobert, J., Barbault, R. (Eds.), Aspects of the Genesis and Maintenance of Biological Diversity. Oxford University Press, Oxford, pp. 278-291.

Excoffier, L., Smouse, P.E., Quattro, J.M., 1992. Analysis of molecular variance inferred from metric distances among DNA haplotypes: application to human mitochondrial DNA restriction data. Genetics 131, 479-491.

Frankham, R., 1997. Do island populations have less genetic variation than mainland populations? Heredity 78, 311-327.

Gaudeul, M., Taberlet, P., Till-Bottraud, I., 2000. Genetic diversity in an endangered alpine plant, Eryngium alpinum L. (Apiaceae), inferred from amplified fragment length polymorphism markers. Mol. Ecol. 9, 1625-1637.

Grant, P.R., Grant, B.R., 1997. Genetics and origin of bird species. Proc. Natl. Acad. Sci. USA 94, 7768-7775.

Hamrick, J.L., Godt, M.J.W., Sherman-Broyle, S.L., 1992. Factors influencing levels of genetic diversity in woody plant species. In: Asams, W., Strauss, S., Copes, D., Griffin, A.R. (Eds.), Population Genetics of Forest Trees. Kluwer Academic Publisher, Netherlands, pp. 95-124.

Hsieh, C.F., 2002. Composition, endemism and phytogeographical affinities of the Taiwan flora. Taiwania 47, 298-310.
Hsieh, C.F., Shen, C.F., Yang, K.C., 1994. Introduction to the flora of Taiwan, 3: floristics, phytogeography, and vegetation. Flora of Taiwan, second ed., vol. 1 (ed. by Editorial Committee of the Flora of Taiwan), Editorial Committee of the Flora of Taiwan, Taipei. pp. 7-18.

Huang, S.F., Hwang, S.Y., Wang, J.C., Lin, T.P., 2004. Phylogeography of Trochodendron aralioides (Trochodendraceae) in Taiwan and its adjacent areas. J. Biogeogr. 31, 1251-1259.

Hwang, S.Y., Lin, H.W., Kuo, Y.S., Lin, T.P., 2001. RAPD variation in relation to population differentiation of Chamaecyparis formosensis and Chamaecyparis taiwanensis. Bot. Bull. Acad. Sin. 42, 173179.

Hwang, S.Y., Lin, T.P., Ma, C.S., Lin, C.L., Chung, J.D., Yang, J.C., 2003. Postglacial population growth of Cunninghamia konishii (Cupressaceae) inferred from phylogeographical and mismatch analysis of chloroplast DNA variation. Mol. Ecol. 12, 2689-2695.

Jaccard, P., 1908. Nouvelles researches sur la distribution florale. Bull. Soc. Vaud. Sci. Nat. 44, 223-270.

Johnson, K.P., Adler, F.R., Cherry, J.L., 2000. Genetic and phylogenetic consequences of island biogeography. Evolution 54, 387-396.

Keiper, F.J., McConchie, R., 2000. An analysis of genetic variation in natural populations of Sticherus flabellatus [R. Br. (St John)] using amplified fragment length polymorphism (AFLP) markers. Mol. Ecol. 9, 571-581.

Krauss, S., 2000. Accurate gene diversity estimates from amplified fragment length polymorphism (AFLP) markers. Mol. Ecol. 9, 1241-1245.

Larson, S.R., Cartier, E., McCracken, C.L., Dyer, D., 2001. Mode of reproduction and amplified fragment length polymorphism variation in purple needlegrass (Nassella pulchra): utilization of natural germplasm sources. Mol. Ecol. 10, 1165-1177.

Lin, T.P., 2001. Allozyme variations in the Michelia formosana (Kanehira) Masamune (Magnoliaceae), and the inference of a glacial refugium in Taiwan. Theor. Appl. Genet. 102, 450-457.

Lin, T.P., Cheng, Y.P., Huang, S.G., 1997. Allozyme variation in four geographic areas of Cinnamomum kanehirae. J. Hered. 88, 433-438.

Lin, T.P., Lu, C.S., Chung, Y.L., Yang, J.C., 1993. Allozyme variation in four populations of Taiwania cryptomerioides in Taiwan. Silv. Genet. 42, 278-284.

Lin, T.P., Wang, C.T., Yang, J.C., 1998. Comparison of genetic diversity between Cunninghamia konishii and C. lanceolata. J. Hered. 89, 370-373.

Liu, T., 1966. Study on the phytogeography of the conifers and Taxads of Taiwan. Bull. Taiwan For. Res. Inst. No. 122.

Liu, E., Furnier, G.R., 1993. Comparison of allozyme, RFLP, and RAPD markers for revealing genetic variation within and between trembling aspen and bigtooth aspen. Theor. Appl. Genet. 87, 97105.

Lu, S.Y., Peng, C.I., Cheng, Y.P., Hong, K.H., Chiang, T.Y., 2001. Chloroplast DNA phylogeography of Cunninghamia konishii (Cupressaceae), an endemic conifer of Taiwan. Genome 44, 797807.

Miller, M.P., 1997a. Tools for Population Genetic Analysis (TFPGA), Version 1.3. A Windows Program for the Analysis of Allozyme and Molecular Population Genetic Data. Department of Biological Science, Northern Arizon University, Flagstaff, AZ.

Miller, M.P., 1997b. Amova-PREP A Program for the Preparation of Input Files for use With WINAmova. Department of Biological Science, Northern Arizon University, Flagstaff, AZ.

Müller-Starck, G., Liu, Y.Q., 1989. Genetics of Cunninghamia lanceolata Hook. 2. Genetic variation within and betweem two provenance samples. Silv. Genet. 38, 172-177.

Muluvi, G.M., Sprent, J.I., Soranzo, N., Provan, J., Odee, D., Folkard, G., McNicol, J.W., Powell, W., 1999. Amplified fragment length polymorphism (AFLP) analysis of genetic variation in Moringa oleifera Lam. Mol. Ecol. 8, 463-470. 
Nei, M., 1978. Estimation of average heterozygosity and genetic distance from a small number of individuals. Genetics 89, 583-590.

Nei, M., 1987. Molecular Evolutionary Genetics. Columbia University Press, New York.

Neigel, J.E., 1997. A comparison of alternative strategies for estimating gene flow from genetic markers. Annu. Rev. Ecol. Syst. 28, 105-128.

Newton, A.C., Allnutt, T., Gillies, A.C.M., Lowe, A., Ennos, R.A., 1999. Molecular phylogeography, intraspecific variation and the conservation of tree species. TREE 14, 140-145.

Palacios, C., Kresovich, S., González-Candelas, F., 1999. A population genetic study of the endangered plant species Limonium dufourii (Plumbaginaceae) based on amplified fragment length polymorphism (AFLP). Mol. Ecol. 8, 645-657.

Petit, R.J., Aguinagalde, I., de Beaulieu, J.L., Bittkau, C., Brewer, S., Cheddadi, R., Ennos, R., Fineschi, S., Grivet, D., Lascoux, M., Mohanty, A., Muller-Starck, G., Demesure-Musch, B., Palme, A., Martin, J.P., Rendell, S., Vendramin, G.G., 2003. Glacial refugia: hotspots but not melting pots of genetic diversity. Science 300 , $1563-1565$.

Powell, W., Morgante, M., Andre, C., Hanafey, M., Vogel, J., Tingey, S., Rafalski, A., 1996. The comparison of RFLP, RAPD, AFLP and SSR (microsatellite) markers for germplasm analysis. Mol. Breed. 2, 225-238.

Schaal, B.A., Hayworth, D.A., Olsen, K.M., Rauscher, J.T., Smith, W.A., 1998. Phylogeographic studies in plants: problems and prospects. Mol. Ecol. 7, 465-474.

Silvertwon, J., 2004. The ghost of competition past in the phylogeny of island endemic plants. J. Ecol. 92, 168-173.

Sneath, P.H.A., Sokal, R.R., 1973. Numerical Taxonomy. Freeman, San Francisco, CA, p. 573.

Steinhoff, R.J., Joyce, D.G., Fins, L., 1983. Isozyme variation in Pinus monticola. Can. J. For. Res. 13, 1122-1132.

Sue, C.Y., Fang, K., Huang, S., 2000. Patterns of genetic variation of Alnus formosana in Taiwan. Taiwania 45, 95-106.
Taberlet, P., Fumagalli, L., Wust-Saycy, A.G., Cosson, J.F., 1998. Comparative phylogeography and postglacial colonization routes in Europe. Mol. Ecol. 7, 453-464.

Travis, S.E, Maschinski, J., Keim, P., 1996. An analysis of genetic variation in Astragalus cremnophylax var. cremnophylax, a critically endangered plant, using AFLP markers. Mol. Ecol. 5, 735745

Tsukada, M., 1967. Vegetation in subtropical Formosa during the Pleistocene glaciation and the Holocene. Palaeogeogr. Palaeocl. Palaeoecol. 3, 49-64.

Vos, P., Hogers, R., Bleeker, M., Reijans, M., Van De Lee, T., Hornes, M., Frijters, A., Pot, J., Peleman, J., Kuiper, M., Zabeau, M., 1995. AFLP: a new technique for DNA fingerprinting. Nucleic Acids Res. 23, 4407-4414.

Widmer, A., Lexer, C., 2001. Glacial refugia: sanctuaries for allelic richness, but not for genetic diversity. TREE 16, 267-269.

Wu, E., Huang, S., Wang, J.C., Tong, W.F., 2001. Allozyme variation and the genetic structure of populations of Trochodendron aralioides, a monotypic and narrow geographic genus. J. Plant Res. 114, $45-57$.

Yang, J.C., Lin, T.P., Cheng, C.C., Kung, F.H., 2000. Geographic variation of China fir (Cunninghamia lanceolata (Lamb.) Hook) in Taiwan: analysis of provenance division by ecotypes and by provinces. Taiwan J. For. Sci. 15, 303-315.

Yeh, F.C., Khalil, M.A.K., El-Kassaby, Y.A., Trust, D.C., 1986. Allozyme variation in Picea mariana from Newfoundland: genetic diversity, population structure, and analysis of differentiation. Can. J. For. Res. 16, 713-720.

Yeh, F.C., Shi, J., Yang, R., Hong, J., Ye, Z., 1994. Genetic diversity and multilocus associations in Cunninghamia lanceolata (Lamb.) Hook from the People's Republic of China. Theor. Appl. Genet. 88, 465-472.

Yu, S.T., 1996. Provenance test and geographic variation of China fir. Contem. Silvi. 11, 41-48 (In Chinese). 